\title{
EMPLOYERS' MIXED SIGNALS TO WOMEN IN IT: UNCOVERING HOW GENDER EQUALITY IDEALS ARE CHALLENGED BY ORGANIZATIONAL CONTEXT
}

\author{
Hilde G. Corneliussen and Gilda Seddighi \\ Western Norway Research Institute, Box 163, 6851 Sogndal, Norway
}

\begin{abstract}
Digitalization across sectors drives an increasing demand for IT specialists. Women, however, still make up a small part of computing communities, IT education and work - in the US and across Europe. The "gender equality paradox" is a label for women's underrepresentation in STEM disciplines, particularly in IT, that seems to be more extreme in highly gender egalitarian cultures. It has been suggested that the paradox is a result of women's choices in wealthy countries with a high degree of individual freedom. However, our research suggests that there is another side to this paradox, thus demonstrating the importance to recognize how other groups affect women's participation in IT. Our study of attitudes towards women's underrepresentation in IT among IT employers and organizations uncovers mixed signals from these actors, as they both welcome and doubt women in IT. Employers' negotiation of the meaning of women's underrepresentation in IT leaves little space for gender equality actions. While this can have major consequences for women's careers in computing and IT work, it also illustrates a central mechanism of the "gender equality paradox" characterized by a widely accepted norm of gender equality existing alongside employers' skepticism to the goal of gender balance in computing.
\end{abstract}

\section{KEYWORDS}

IT Work, Employers, Gender Equality, Paradox, Discursive Resources

\section{INTRODUCTION}

Digitalization across sectors drives an increasing demand for IT specialists (EIGE, 2018). Women, however, still make up a small part of computing communities, IT education and work - in the US and across Europe (Bailey \& Riley, 2018; EUROSTAT, 2019; Simonsen \& Corneliussen, 2020). Women's underrepresentation in IT has often been depicted as a challenge concerning girls and women (Wajcman, 2004). However, it is also important to recognize how other groups affect women's participation in IT. Our study explores attitudes towards women's underrepresentation in IT among IT employers and organizations. The research questions guiding this chapter are: How do IT employers and organizations perceive the underrepresentation of women in IT? Do they consider it a goal to increase women's participation in IT, and if so, which strategies or actions do they engage for improving the gender balance in IT work in their own organization?

The analysis uncovers mixed signals from these actors as it shows a tendency for the employers to accept the norm of gender equality, while simultaneously negotiating, and even questioning, the goal of recruiting more women to IT work. This leaves the organizations with little space for gender equality actions. Based on dialogue meetings in 12 IT organizations, this paper analyses these attitudes that work as barriers to gender equality work in the IT sector. While this could be identified as a type of "resistance" towards gender equality, we rather suggest analyzing this through a more productive notion of "discursive resources" that individuals use to make sense of their context (Dick, 2004). Applying a unique wide and cross sectoral perspective on central actors in the field of IT work makes this study able to identify an underlaying mechanism of the gender equality paradox. 


\subsection{A Gender Equality Paradox}

Despite increasing digitalization and exciting job opportunities for IT expertise, the proportion of women is developing slowly, in some places even negatively (National Science Foundation, 2019). Women's underrepresentation in IT is recognized as even more extreme in wealthier and more egalitarian countries such as the Nordic countries in general and Norway in particular (Chow \& Charles, 2019; Stoet \& Geary, 2018), which is the object of our study.

The strong notion of gender equality in the Nordic countries is reflected in rules and regulations aimed to fight gender discrimination and to secure equal rights and opportunities (Skjeie \& Teigen, 2005). In the face of this national gender equality regime, the underrepresentation of women has been narrated as a "gender equality paradox" (Chow \& Charles, 2019; Stoet \& Geary, 2018). It has been suggested that the phenomenon is caused by the high level of gender equality itself, creating freedom not only from gender discrimination, but also a "right to choose poorly paid female-labeled career paths" (Charles \& Bradley, 2006). Other explanations suggest that the national level of wealth makes it less urgent for women in more affluent societies to aim for well-paid jobs (Stoet \& Geary, 2018). While such explanations place the responsibility on girls and women, research has demonstrated a perseverance in how masculine cultures of computing (Blum et al., 2007), gender stereotypes associating IT with men (Master et al., 2016) and "the perception of ICT jobs as a playground for men" (EIGE, 2018) have a negative impact on women's entry into IT careers.

Gender equality as a goal and the welfare state as an active force pushing towards this goal characterizes the Nordic countries (Borchorst \& Siim, 2008; Hernes, 1987). The widely accepted ideal of gender equality and inclusion of women in working life has become something "we cannot not want" (Brown, 2000), but still it can be difficult to transform into active practices of inclusion (Holli et al., 2005). A political goal of "mainstreaming", making gender equality a general principle in organizations has been criticized for making it everybody's task in a way that makes it nobody's responsibility (Teigen \& Eggebø, 2017). Even in a context where the state actively promotes gender equality, like in Norway, there is found little focus on this among employers when there are no incentives for such engagement (Nordberg, 2019). Furthermore, there are no routines for enforcing the employers' statutory duty to secure gender equality in their organizations (Ibid.). It is, however, recognized as vital that the IT sector is involved in work to improve the gender balance in IT, and also, since men hold at least $75 \%$ of IT jobs, men must become "advocates", Bailey and Riley emphasize (2018). The first step is to acknowledge that there is a problem so that changes can be made in strategies for recruiting women to IT jobs (Ibid.; Corneliussen \& Seddighi, 2019).

A low motivation to engage in gender equality work, as well as outright resistance towards such initiatives, have been recognized in studies of male dominated occupations (Johansson et al., 2019). Meritocratic principles, seeing opportunities and promotion as resting on individual's competence, is often considered to "solve" gender inequality by assuming that participation is based on individuals' efforts rather than being affected by discriminatory processes (Powell et al., 2018). A similar situation can be recognized in IT, where a low proportion of women has been used as a documentation for women's low interest rather than seeing it as a result of discriminatory practices (Corneliussen \& Prøitz, 2016). Within such perspectives, positive actions for gender equality can even be perceived as enhancing the problem instead of solving it (Johansson et al., 2019). Contrary to this view, evidence suggests that interventions are necessary to achieve a better gender balance in the most male dominated fields of IT (National Science Foundation, 2019; Simonsen \& Corneliussen, 2020; Vabø et al., 2012). Meanwhile, gender stereotypes characterizing women with a weak relationship to IT (Payton \& Berki, 2019) continue to have effect. Stereotypes make it difficult to associate women with IT expertise in a culture where they tend to fail the "if-can"-test (Corneliussen et al., 2019). The "if-can"-test, West and Zimmerman (1987) claim, reflects a tendency to identify people as belonging to a certain category if they can be perceived as belonging to this category. This challenge is of particular relevance to fields like IT which are strongly associated with men (Payton \& Berki, 2019), illustrated by our findings showing employers' and organizations' doubts about women's rightful belonging in IT jobs.

The analysis below explores how employers and organizations involved in IT research, development, and innovation perceive and deal with the underrepresentation of women in IT in Norway. The findings illustrate how a national gender equality regime is renegotiated by relevant employers and organizations challenging the meaning of women's underrepresentation as well as the ideal of gender equality in IT. 


\section{METHODS}

\subsection{Case Study}

Our study included 13 women and 10 men from a total of 12 organizations, private as well as public, with a shared interest in IT in research, development, and innovation. "IT" here refers to a wide notion of expertise in fields of information and communication technology including computing and other adjoining disciplines. The study had a cross-sectoral profile, as we observed a growing engagement of IT specialists in new sectors and industries (EUROSTAT, 2019). Some of the participating organizations represented the traditional private IT sector, while others were public bodies, research funders, and research institutes with IT and digitalization as a key area. Thus, together they represent a wide specter of organizations that contribute to shaping IT work. The 23 men and women participating were appointed by the organizations. They were leaders and managers for the organizations, head of IT or HR departments or had other administrative positions, while some represented the professional IT staff. When analyzing the material we found more similarities than differences between the sectors and industries; we therefore only occasionally refer to the sector in the analysis presented below.

The organizations were invited to dialogue meetings to discuss the underrepresentation of women in computing and how to improve the situation. The meetings aimed to explore as well as create dialogue with the organizations to learn from their practices and they loosely followed a focus group design where the aim is to study how meaning is created in a social context (Patton, 2002). Six main questions were presented on a piece of paper on the table to start the discussion, pertaining to the meaning of IT for the organization, gender distribution in the organization and across positions, strategies to recruit women, and gender equality goals and actions.

\subsection{Analyzing Contextualized Attitudes as Discursive Resources}

The study is based on a theoretical tradition of Feminist Technology Studies (FTS) (Bray, 2007) recognizing both gender and technology as socially constructed and shaping or co-constructing each other (Corneliussen, 2011; Kelan, 2007). The analytical method engaged focusses on the discursive level (Livholts \& Tamboukou, 2015) of the dialogue meetings, exploring how meaning of gender and IT are constructed and negotiated. As will be elaborated below, the organizations' responses involved a type of negotiation that could be perceived as a form of resistance to gender equality in IT. However, labelling this as resistance involves a risk of misrepresenting how the organizations perceived the situation: they did not consider their response to the situation a rejection of gender equality norms. It is more productive to analyze the mechanisms at play here as productive "discursive resources" that the individual engages to understand and negotiate the question of gender equality in their own organizational context (Corneliussen \& Seddighi, 2019; Dick, 2004). This helps to understand the mixed messages from the organizations that simultaneously welcome and doubt women's entry into IT jobs.

The examples discussed below should not be considered the organizations' formal attitudes but rather represent individual voices. However, these voices suggest that the organizations do not have clear guidelines for working with gender equality (Nordberg, 2019).

\section{RESULTS: ALTERNATIVE APPROACHES TO WOMEN'S UNDER-REPRESENTATION}

In the invitation to the dialogue meetings, we introduced some "fixed points" of departure by recognizing that women are underrepresented in computing and it is an ideal to get more women into computing, which, in turn, means that gender equality action is required. All the organizations initially agreed with the above definitions of the situation and the goal. However, when reflecting on how this goal could be realized in their own organization, other ways of seeing the situation were presented. Thus, during the discussion, alternative approaches were introduced, as shown in the table below, presenting how the meaning of gender equality was 
negotiated in relation to their organizational context. This involved alternative perceptions of women's underrepresentation, alternative ways of seeing the goal of increasing women's participation, and, consequently, the effect this had on their attitudes towards engaging in gender equality actions.

Table 1. Examples of organizations negotiating the ideal of gender equality in IT

\begin{tabular}{|c|c|c|c|c|}
\hline $\begin{array}{l}\text { Approaches to } \\
\text { gender equality } \\
\text { in IT }\end{array}$ & $\begin{array}{l}\text { Organizational context for } \\
\text { gender equality }\end{array}$ & $\begin{array}{l}\text { Perception of } \\
\text { women's under- } \\
\text { representation }\end{array}$ & $\begin{array}{l}\text { Perception of the } \\
\text { ideal to increase } \\
\text { women's } \\
\text { participation }\end{array}$ & $\begin{array}{l}\text { Attitudes } \\
\text { towards gender } \\
\text { equality action }\end{array}$ \\
\hline \multirow{3}{*}{$\begin{array}{l}\text { 1. Gender } \\
\text { equality is not a } \\
\text { challenge }\end{array}$} & $\begin{array}{l}\text { a) "We already have gender } \\
\text { balance, but not in IT" }\end{array}$ & Invisible & Unimportant & Unnecessary \\
\hline & $\begin{array}{l}\text { b) "We employ women in } \\
\text { other positions" }\end{array}$ & Agree & Unimportant & Unnecessary \\
\hline & c) "We have gender equality" & Agree & Agree & Unnecessary \\
\hline \multirow{2}{*}{$\begin{array}{l}\text { 2. Gender is not a } \\
\text { focus }\end{array}$} & $\begin{array}{l}\text { d) "We focus on equality for } \\
\text { other groups" }\end{array}$ & Unimportant & Unimportant & $\begin{array}{l}\text { Yielding for other } \\
\text { goals }\end{array}$ \\
\hline & $\begin{array}{l}\text { e) "We avoid focusing on } \\
\text { women" }\end{array}$ & Agree & Agree & $\begin{array}{l}\text { Gender neutral } \\
\text { (no) strategies }\end{array}$ \\
\hline \multirow{3}{*}{$\begin{array}{l}\text { 3. Men and } \\
\text { women are } \\
\text { different }\end{array}$} & $\begin{array}{l}\text { f) "Women have other } \\
\text { interests" }\end{array}$ & Agree & Questioning goal & $\begin{array}{l}\text { Do we need } \\
\text { women? }\end{array}$ \\
\hline & g) "Men fit IT work better" & Agree & Questioning goal & $\begin{array}{l}\text { Do we want } \\
\text { women? }\end{array}$ \\
\hline & h) "We just want the best" & Agree & Questioning goal & $\begin{array}{l}\text { Competence } \\
\text { before gender }\end{array}$ \\
\hline \multirow{2}{*}{$\begin{array}{l}\text { 4. Indifference } \\
\text { and passivity }\end{array}$} & i) "It will pass" & Agree & Agree & Wasted energy \\
\hline & j) "It is not a requirement" & Agree & Agree & Not required \\
\hline
\end{tabular}

\subsection{Gender Equality is Not Perceived as a Relevant Challenge}

Gender imbalance in IT is not necessarily perceived as a relevant identification of gender inequality in an organization. The table shows three examples of "discursive resources" used to argue that gender equality is not a challenge as it is already secured in the organization at large. The first two suggest that the problem is already solved by transferring the issue to the overall organization rather than IT.

a) "We already have gender balance, but not in $I T$ " is a reaction typically found in public sector organizations that employ many women (SSB, 2018). This approach disguises gender imbalance in IT and renders it unimportant: "We have many women in different positions and with higher education, so we don't experience it the same way. So, I think that we have not considered it necessary to have more women in IT". Changing focus from IT workers to the overall organization allows for a claim that gender balance has already been achieved; therefore, it is less important to work towards further changes in IT recruitment.

b) "We employ women in other positions" is a similar logic found in the private sector, some with no women in IT positions: "Our main initiative to recruit more women is to focus more on roles in HR." Their strategy is primarily targeting a better gender balance in the work environment rather than in IT jobs. Having female employees erodes the need for women in IT, another illustrates: "We have one woman in IT development ... she has other women around in other positions. So that means, perhaps it is not so important to have more women in IT." Gender equality in these cases is more about the social environment and less about women working with IT.

c) "We have gender equality" reflects attitudes in an organization with no women in IT positions. They renegotiate what gender equality means, suggesting that it is a matter of how people are treated, rather than who works with IT: "Everybody is treated the same, we don't think much about it. [...] We don't see any difference between our co-workers". Defining gender equality as something that already exists almost automatically, makes actions aiming at increasing the number of women in IT positions less relevant: women are invited, and they are treated "the same", they are just not coming. Gender researchers have, however, warned that similar treatment does not necessarily represent equality when the starting point for men and women is one of difference (Kvande \& Rasmussen, 1993 (1990)). 
The examples above illustrate how the initial claim of women's underrepresentation in IT is renegotiated by identifying the challenge as already solved in their organizations. They do not reject the gender equality ideal as such, but rather engage "discursive resources" to make sense of the ideal within their own organizational context, concluding that it is unnecessary to engage in gender equality actions.

\subsection{No Focus on Gender}

Gender equality is a difficult topic to address. There are few guidelines for employers, and gender issues compete with other concerns.

d) "We focus on equality for other groups" is a claim that is supposed to justify less focus on gender and more on other groups, for instance ethnic minorities. "That is where we cannot reach our goals", one organization explains. Not only the overall organization, rather than IT jobs, but also other types of inclusion and "equality work" takes the focus away from women's underrepresentation in IT.

e) "We avoid focusing on women" illustrates a fear of drawing attention to their failure in hiring women: "We don't believe in the typical 'women are encouraged to apply'. That is a bad recipe for making women apply." Their strategy for recruiting women is rather based on a universal "non-gendered" perspective, as they are convinced that targeting women "will result in the opposite effect" - despite their lack of success in recruiting women so far.

The examples above illustrate how gender equality often loses out to other, apparently more pressing, matters (Skjeie \& Teigen, 2003). It also illustrates the challenges for the organizations that, despite a national gender equality regime, have little knowledge of how to implement a gender equality strategy.

\subsection{Men and Women are Different}

This approach is based on perceptions of gender as a difference illustrating how gender equality norms are "disarmed", or even rejected, with references to stereotypical perceptions of men's and women's relationships to IT. In the three examples, the organizations' representatives realize that women are underrepresented in IT, however, seeing gender as a difference between men and women in terms of interest, abilities and competences in IT, makes them question the ideal of recruiting more women.

f) "Women have other interests" reflects a perception of gender differences as a cultural product that rather schools and parents need to address: "Our greatest challenge is something that we cannot change, and that is the fact that we have a society that makes girls do 'girls' things' and boys do 'boys' things'." Change is out of reach for the organizations, leaving them with the question: "Do we really need more women in IT?"

g) "Men fit IT work better" is a related perception, however, this time calling upon "natural" differences between men and women. Using himself as an example, one of the men explains that "boys are very single-minded and very focused on their interests", thus building their IT competence already as teenagers. Describing this as boys' advantage over girls who lack this background, makes it all but impossible for girls to compete on this arena.

h) "We just want the best" builds on the attitudes described above and makes gender equality appear to conflict with highly skilled competence in IT. "The most important thing is to get the right person, and if that happens to be a woman, that is great". Although women are wanted in IT, expectations of women remain low and gender equality appears to require compromising with the need for competence - as if women and IT qualifications are not expected to exist in pair.

\subsection{Indifference and Passivity}

The final approach illustrates organizations that agree with the gender equality ideal, they are just not convinced that it is worth the effort.

i) "It will pass" sees the underrepresentation of women as a temporary problem that will solve itself, thus any gender equality action would be wasted energy.

j) "It is not a requirement" and therefore "it is not an explicit part of our mission now" reflects that policies and regulations aiming to promote gender equality in employment is followed by few and vague requirements for employers. Also, there are no public sanctions against the absence of such engagement (Nordberg, 2019). 
The employers agree that women's situation as underrepresented in IT should be improved, but as they find no reason for active engagement, passivity is their actual response.

\section{MIXED MESSAGES OF GENDER EQUALITY IN IT}

The analysis above shows how the representatives for the organizations that participated in dialogue meetings, even from public sector organizations with more requirements to gender equality measures and processes, redefined the call for gender equality in IT in ways that made gender equality actions a non-existing feature.

Table 1 illustrates that while only two of the examples (a and d) renegotiate the initial description of women as underrepresented in IT, six renegotiate the need to recruit more women to IT jobs. This demonstrates how many of the employers question the need for increasing women's participation in IT, and furthermore, that none of them embraced the call for gender equality action. The most remarkable feature, however, is that even when agreeing that women are underrepresented and seeing it as a goal to improve the situation, the employers and organizations find little reason to engage in action that may change the situation, some even seem to argue that changes are not really desirable. This is a critical point to observe, because it means that gender equality as a norm is widely accepted, while the organizational contexts undermine the will to deal with women's underrepresentation in IT.

The examples analyzed above are not unique and it is likely that related articulations and renegotiations can be found in other organizations. A more generic description of the mechanisms at play could look like the figure below: the national gender equality regime creates expectations to employers' active work to improve the gender imbalance in IT, reflected in rules and regulations. However, gender balance in IT is not a specific requirement and there are few and vague guidelines for the organizations for engaging in gender equality work in general. The organizations' representatives see the request for gender equality in the context of their organization, introducing internal and external factors that contribute to modifying the understanding of women's underrepresentation and whether or not it is worth changing. This process introduces doubt and alternative ways of perceiving the situation, resulting in limited space for organizations to find motivation to engage in gender equality actions.
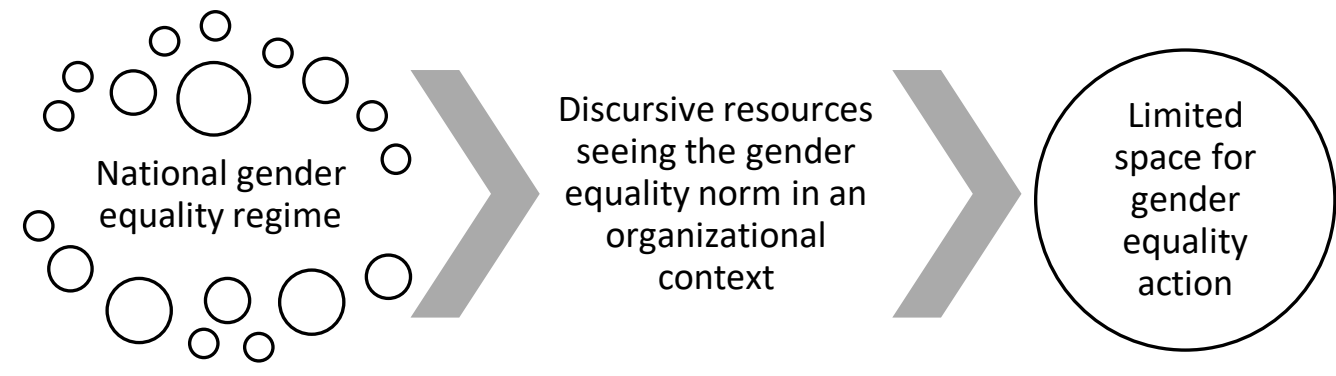

Figure 1. A model of renegotiation of the gender equality norm in an organizational context

The mechanism at play illustrates how gender imbalance in IT is simultaneously visible and invisible: it is indeed recognized, but as a result of cultural perceptions and gender stereotypes, it is not necessarily considered worthy of change (Corneliussen \& Prøitz, 2016).

Stereotyping women in IT makes it particularly difficult for women to be recognized as IT experts - or to pass the "if-can"-test in IT (Corneliussen et al., 2019). It is vital to recognize that women's participation is not only challenged by the most extreme attitudes, like identifying men with a unique masculine way of achieving IT competence. Even more problematic, many of the employers and organizations did recognize women's underrepresentation, but did not recognize this as a problem, which means that the gender equality norm can co-exist with the very attitudes that undermine the norm. This, we suggest, provides a better explanation to the gender equality paradox: the national gender equality regime promoting gender egalitarian norms and ideals is not disputed, but rather confirmed and simultaneously renegotiated to fit the organizational contexts, yet drained of the potential to spark change. 


\section{CONCLUSION: CONTEXTUALIZED KNOWLEDGE}

We need more knowledge about how employers and organizations hiring IT experts perceive and deal with gender equality in IT, and our study suggests a need to understand the perspectives of the organizations better. Analyzing the alternative approaches presented above as "resistance" to gender equality would probably not have produced knowledge that the organizations could recognize. On the other hand, analyzing the approaches as "discursive resources" increases our understanding of how the organizations proceed when challenged to reflect on inclusion and gender equality in their own organizational context. This contributes to building the knowledge that is necessary for helping these organizations to develop future strategies to tackle the gender imbalance in IT.

\section{ACKNOWLEDGEMENT}

This is partly based on and a reworked version of the analysis reported in Corneliussen \& Seddighi, 2019, published in Norwegian under the Creative Commons CC-BY-NC 4.0. We want to thank the representatives for IT companies and organizations that participated in dialogue meetings. The work with this article was funded by Nordwit, a Nordic Centre of Excellence, studying women in tech-driven careers in the Nordic countries. Read more about Nordwit: https://nordwit.com/.

\section{REFERENCES}

Bailey, M., \& Riley, S., 2018. 2018 Women in Tech: Unconscious Bias, Parity, and the Path Forward, https://mailchi.mp/57c92dac9f60/2018-women-in-tech-unconscious-bias-report.

Blum, L., Frieze, C., Hazzan, O., \& Dias, M. B., 2007. A Cultural Perspective on Gender Diversity in Computing. In C. J. Burger, E. G. Creamer, \& P. S. Meszaros (Eds.), Reconfiguring the Firewall. Recruiting Women to Information Technology across Cultures and Continents (109-133), Wellesley, MA: A K Peters, LTD.

Borchorst, A., \& Siim, B., 2008. Women-friendly policies and state feminism: Theorizing Scandinavian gender equality. Feminist Theory, 9(2), 207-244.

Bray, F., 2007. Gender and technology. Annual Review of Anthropology, 36, 37-53.

Brown, W., 2000. Suffering rights as paradoxes. Constellations, 7, 208-229. doi:https://doi.org/10.1111/1467-8675.00183

Charles, M., \& Bradley, K., 2006. A Matter of Degrees: Female Underrepresentation in Computer Science Programs Cross-Nationally. In J. M. Cohoon \& W. Aspray (Eds.), Women and Information Technology. Research on Underrepresentation (183-203), Cambridge, Massachusetts, London, England: MIT Press.

Chow, T., \& Charles, M., 2019. An Inegalitarian Paradox: On the Uneven Gendering of Computing Work around the World. In C. Frieze \& J. L. Quesenberry (Eds.), Cracking the Digital Ceiling: Women in Computing around the World (25).

Corneliussen, H. G., 2011. Gender-Technology Relations: Exploring Stability and Change, Basingstoke: Palgrave Macmillan.

Corneliussen, H. G., \& Prøitz, L., 2016. Kids Code in a rural village in Norway: could code clubs be a new arena for increasing girls' digital interest and competence? Information, Communication \& Society, 19(1 (Special Issue: Understanding Global Digital Cultures)). doi:https://doi.org/10.1080/1369118X.2015.1093529

Corneliussen, H. G., \& Seddighi, G., 2019. "Må vi egentlig ha flere kvinner i IKT?" Diskursive forhandlinger om likestilling i IKT-arbeid. Tidsskrift for kjønnsforskning, 43(4), 273-287.

Corneliussen, H. G., Seddighi, G., \& Dralega, C. A., 2019. Women's Experience of Role Models in IT: Landmark women, substitutes, and supporters. In Ø. Helgesen, E. Nesset, G. Mustafa, P. Rice, \& R. Glavee-Geo (Eds.), Modeller: Fjordantologien 2019: Universitetsforlaget.

Dick, P., 2004. Resistance to diversity initiatives. In R. Thomas, A. Mills, \& J. H. Mills (Eds.), Identity politics at work: Resisting gender and gendering resistance (67-84), Oxfordshire, New York: Routledge.

EIGE, 2018. Women and men in ICT: a chance for better work-life balance - Research note, Luxembourg: EIGE: European Institute for Gender Equality, Publications Office of the European Union.

EUROSTAT, 2019. ICT specialists in employment - Statistics Explained, https://ec.europa.eu/eurostat/statisticsexplained/index.php/ICT_specialists_in_employment. 
Hernes, H. M., 1987. Welfare state and woman power. Essays in state feminism, Oslo: Norwegian University Press.

Holli, A. M., Magnusson, E., \& Rönnblom, M., 2005. Critical studies of Nordic discourses on gender and gender equality. Nordic Journal of Women's Studies, 13(03), 148-152. doi:https://doi.org/10.1080/08038740600590442

Johansson, K., Andersson, E., Johansson, M., \& Lidestav, G., 2019. The Discursive Resistance of Men to Gender-equality Interventions: Negotiating "Unjustness" and "Unnecessity" in Swedish Forestry. Men and Masculinities, 177-196. doi:https://doi.org/10.1177\%2F1097184X17706400

Kelan, E. K., 2007. TOOLS AND TOYS : Communicating gendered positions towards technology. Information, Communication \& Society, 10(3), 358-383. doi:10.1080/13691180701409960

Kvande, E., \& Rasmussen, B., 1993 (1990). Nye kvinneliv. Kvinner i menns organisasjoner [New Women's Lives. Women in Men's Organizations], Oslo: Ad Notam.

Livholts, M., \& Tamboukou, M., 2015. Discourse and Narrative Methods, Los Angeles: SAGE.

Master, A., Cheryan, S., \& Meltzoff, A. N., 2016. Computing whether she belongs: Stereotypes undermine girls' interest and sense of belonging in computer science. Journal of Educational Psychology, 108(3), 424.

National Science Foundation, 2019. Women, Minorities, and Persons with Disabilities in Science and Engineering: https://ncses.nsf.gov/pubs/nsf19304/digest.

Nordberg, T. H., 2019. Arbeidsgivers ansvar for likestilling i arbeidslivet. Tidsskrift for kjønnsforskning, 43(2), 90-107. doi:https://doi.org/10.18261/issn.1891-1781-2019-02-03

Patton, M. Q., 2002. Qualitative research and evaluation methods, Thousand Oakes, London, New Delhi: Sage Publications.

Payton, F. C., \& Berki, E., 2019. Countering the negative image of women in computing. Commun. ACM, 62(5), 56-63. doi:10.1145/3319422

Powell, S., Ah-King, M., \& Hussénius, A., 2018. 'Are we to become a gender university?' Facets of resistance to a gender equality project. Gender, Work \& Organization, 25(2), 127-143. doi:https://doi.org/10.1111/gwao.12204

Simonsen, M., \& Corneliussen, H. G., 2020. What Can Statistics Tell About the Gender Divide in ICT? Tracing Men and Women's Participation in the ICT Sector Through Numbers. In D. Kreps, T. Komukai, G. TV, \& K. Ishii (Eds.), Human-Centric Computing in a Data Driven Society: Springer.

Skjeie, H., \& Teigen, M., 2003. Menn imellom. Mannsdominans og likestillingspolitikk, Oslo: Gyldendal akademisk.

Skjeie, H., \& Teigen, M., 2005. Political constructions of gender equality: Travelling towards... a gender balanced society? Nordic Journal of Women's Studies, 13(03), 187-197. doi:https://doi.org/10.1080/08038740600590004

SSB, 2018. Women and men in Norway, Satistics Norway.

Stoet, G., \& Geary, D. C., 2018. The Gender-Equality Paradox in Science, Technology, Engineering, and Mathematics Education. Psychological Science, 29(4), 581-593. doi:10.1177/0956797617741719

Teigen, M., \& Eggebø, H., 2017. Debatt: I politikken har klima samme vikeplikt som likestilling. Kilden: kjønnsforskning.no, http://kjonnsforskning.no/nb/2017/2012/klima-samme-vikeplikt-som-likestilling.

Vabø, A., Gunnes, H., Tømte, C., Bergene, A. C., \& Egeland, C., 2012. Kvinner og menns karriereløp i norsk forskning: En tilstandsrapport (8272188201), Rapport 9/2012, NIFU.

Wajcman, J., 2004. TechnoFeminism, Cambridge: Polity Press.

West, C., \& Zimmerman, D. H., 1987. Doing Gender. Gender \& Society, 1(2), 125-151. 